\title{
The Effects of Pornography on Unethical Behavior in Business
}

\author{
Nathan W. Mecham ${ }^{1} \cdot$ Melissa F. Lewis-Western ${ }^{2} \cdot$ David A. Wood $^{3}$
}

Received: 29 January 2018 / Accepted: 4 June 2019 / Published online: 14 June 2019

(c) The Author(s) 2019

\begin{abstract}
Pornography is no longer an activity confined to a small group of individuals or the privacy of one's home. Rather, it has permeated modern culture, including the work environment. Given the pervasive nature of pornography, we study how viewing pornography affects unethical behavior at work. Using survey data from a sample that approximates a nationally representative sample in terms of demographics, we find a positive correlation between viewing pornography and intended unethical behavior. We then conduct an experiment to provide causal evidence. The experiment confirms the survey-consuming pornography causes individuals to be less ethical. We find that this relationship is mediated by increased moral disengagement from dehumanization of others due to viewing pornography. Combined, our results suggest that choosing to consume pornography causes individuals to behave less ethically. Because unethical employee behavior has been linked to numerous negative organization outcomes including fraud, collusion, and other self-serving behaviors, our results have implications for most societal organizations.
\end{abstract}

Keywords Pornography $\cdot$ Ethics $\cdot$ Unethical behavior $\cdot$ Dehumanization

\section{Introduction}

Pornography is not a new activity, but its use has increased significantly over the last 20 years (e.g., Price et al. 2016). As a result, an activity that was once primarily restricted to adolescent boys and a small proportion of adults has become more commonplace even in business settings. It is estimated that 40 million Americans regularly visit pornographic websites (Ropelato 2014). A 2018 survey finds that nearly $60 \%$ of respondents watch pornography at work, with half viewing pornography on a monthly basis and $10 \%$ viewing it daily (McDonald 2018). Indeed, $70 \%$ of all internet

David A. Wood

davidwood@byu.edu

Nathan W. Mecham

nathanwmecham@gmail.com

Melissa F. Lewis-Western

melissa.western@byu.edu

1 Brigham Young University, 540 TNRB, Provo, UT 84602, USA

2 Brigham Young University, 521 TNRB, Provo, UT 84602, USA

3 Brigham Young University, 518 TNRB, Provo, UT 84602, USA pornography traffic occurs between the hours of 9 a.m. and 5 p.m., a time when most people are likely working (Conlin 2000; Covenant Eyes 2015). A recent Bloomberg article concludes that "watching porn at the office is extremely common" (Suddath 2014). In addition to the statistics, there are numerous anecdotal examples of pornography consumption at work. ${ }^{1}$ For example:

During the past 5 years, the SEC OIG (Office of Inspector General) substantiated that 33 SEC employees and or contractors violated Commission rules and policies, as well as the government-wide Standards of Ethical Conduct, by viewing pornographic, sexually explicit or sexually suggestive images using government computer resources and official time (CNN 2010).

For 2 years, a high-level executive at a New England finance company arrived at work each morning, said hello to his secretary, and then shut the door of his roomy, windowed office behind him. Like clockwork, he drew the blinds and tilted his computer screen toward him so that-should anyone suddenly barge in - they couldn't tell what he was doing. For the next

1 The examples we give focus on the government sector because violations of policies are often made known publicly, whereas businesses are often able to conceal from the public the exact reasons for terminations and other negative events. 
$6 \mathrm{~h}$, and sometimes eight, he proceeded to cruise the Internet for the raunchiest porn sites he could find (Conlin 2000).

Using the Freedom of Information Act, the News 4 I-Team obtained investigative records from a dozen federal agencies to gather a sampling of recent cases of computer misuse by employees. The sampling revealed at least 50 cases of large-scale or criminal pornography viewing at those 12 agencies since 2015 , including several in which employees acknowledged spending large chunks of work days surfing for pornography (NBC 2018).

Earlier this year an employee at the U.S. Environmental Protection Agency got caught, almost literally, with his pants down. A special agent from the EPA's Office of Inspector General showed up at the seniorlevel employee's office to find out why he'd stored pornographic images on the network servers. The agent walked in on the guy-you guessed it-watching porn. When pressed, the employee admitted he'd been watching sexy sites for 2 to $6 \mathrm{~h}$ every workday since 2010 (Suddath 2014).

These statistics and anecdotal stories highlight that pornography consumption at work is a significant issue. While managers should be alarmed because of the time and resources wasted due to pornography consumption at work (with some estimating the loss to U.S. companies as high as $\$ 16.9$ billion annually ${ }^{2}$ ), pornography consumption may be even more problematic if it negatively influences other workplace behaviors. Specifically, pornography consumption may influence employees' propensity to behave unethically. Consequently, we investigate the causal relation between viewing pornography and unethical behavior.

We develop a model of how pornography increases unethical behavior based on prior research. Prior research suggests two likely paths for pornography consumption to increase unethical behavior. First, research has found that viewing pornography increases delay discounting (Lawyer 2008; Negash et al. 2016; Van den Bergh et al. 2008; Wilson and Daly 2004). Individuals with greater tendencies to heavily discount future outcomes are willing to give up a larger future benefit for a smaller immediate benefit. Greater delay discounting has been linked to reduced self-control and increased impulsive, short-sighted behavior (Fawcett et al. 2012), which increases unethical behavior (Lee et al. 2017). As such, increases in delay discounting from pornography consumption are expected to increase unethical behavior.

\footnotetext{
2 https://www.webroot.com/us/en/home/resources/tips/digital-famil y-life/internet-pornography-by-the-numbers.
}

Second, prior research finds that moral disengagement increases unethical behavior (e.g., Detert et al. 2008; Gabbiadini et al. 2014). Bandura's (1986) model of moral disengagement includes eight mechanisms ${ }^{3}$ that facilitate moral disengagement. We focus on one-dehumanization ${ }^{4}$ because prior research posits that pornography consumption increases the viewer's propensity to dehumanize others (Fagan 2009; Peter and Valkenburg 2007; Schneider 2000). That is, if pornography consumption increases moral disengagement, then dehumanization is the likely mechanism. Thus, we expect that pornography consumption will increase unethical behavior if it increases employees' tendencies to dehumanize others. In summary, we expect viewing pornography to be positively associated with unethical behavior and for this effect to manifest from increases in delay discounting, dehumanization, or both.

To examine the relation between pornography consumption and unethical behavior, we use two complementary methodologies, a survey and an experiment, that have different validity strengths and weaknesses. The survey allows us to test whether effects are present outside of a laboratorysetting. The experiment provides causal evidence and evidence on the underlying mechanisms (i.e., delay discounting and dehumanization). Together, consistent results across methodologies provide strong evidence that the effects are both causal and generalizable.

First, we conduct a survey using a sample reflective of the U.S. national population in demographics. In this sample of 1083 U.S. adults, we find that $44 \%$ of the sample report that they never view pornography, $24 \%$ report rarely viewing it, $22 \%$ occasionally view it, and $6 \%$ and $4 \%$ view it frequently and very frequently, respectively. We created a hypothetical situation that asked participants how likely they would be to dishonestly abuse a company's policy for personal benefit (i.e., how likely they are to lie for monetary gain). We find a significant, monotonically increasing relation between pornography consumption and willingness to behave unethically (i.e., to lie for monetary gain). This relation is robust to controlling for various demographic characteristics of respondents.

Second, to provide evidence that our results are causal and not just associative in nature and to examine the role of delay discounting and dehumanization as possible mediating variables, we conduct an experiment. For our experiment, we employed participants to complete a task and measured

\footnotetext{
3 The other mechanisms are moral justification, euphemistic labeling, advantageous comparison, displacement of responsibility, diffusion of responsibility, disregarding the consequences, and attribution of blame.

${ }^{4}$ Dehumanization is the psychological process of viewing and treating others like objects or as a means to an end rather than as humans (Papadaki 2010; Saul 2006).
} 
if pornography consumption influenced their willingness to shirk work and lie about work performed-two common unethical workplace behaviors (Rodriguez 2015). To protect participants and yet collect the data necessary to test our hypotheses, we do not expose participants directly to pornography, but rather we asked participants in one experimental condition to recall and describe in detail their last viewing of pornography. This activated pornographic imagery in the minds of those who choose to view pornography and allowed those who do not choose to view it to avoid unwanted exposure. We then instructed participants that their job was to watch all of a 10-min video. The video was boring, thus providing participants with an incentive to skip the video. We later asked participants if they watched the entire video and measured who was lying by recording whether they actually watched the video or not.

The results of the experiment show that participants shirk work (by not watching the video) and lie about work performed $21 \%$ of the time when they recalled their last experience with pornography and only $8 \%$ of the time when they recalled a non-pornographic situation. Thus, viewing pornography increased lying by 2.6 times-a sizable and economically significant effect. Furthermore, we test the two possible mediators for the effect of pornography on unethical behavior-delay discounting and dehumanization. The results of our mediation analysis show only dehumanization as a statistically significant mediator. Pornography use increases viewers' dehumanization of others, which in turn increases viewers' willingness to shirk work and lie for personal benefit.

This paper contributes to the literature in several ways. This is the first study, of which we are aware, that shows the deleterious effects of pornography on unethical behavior. In addition, we can identify at least one mechanism by which pornography causes unethical behavior-by increasing dehumanization of others. Prior research argues that pornography consumption will increase dehumanization, but we are unaware of any causal evidence to this point. Thus, our experimental results support the commonly touted, but untested link between pornography and dehumanization. These results are also important for several aspects of organizational performance. First, Moore et al. (2012) provide evidence that employees' propensity to morally disengage via dehumanization and other disengagement mechanisms leads to unethical organizational behavior including an increased propensity for fraud and other less egregious self-serving behavior. Similarly, Welsh et al. (2015) provide evidence that small ethical infractions pave the way for larger transgressions that lead to fraud and other corporate scandals. ${ }^{5}$

\footnotetext{
${ }^{5}$ Consistent with individual unethical behavior impacting organization outcomes, the 2017 SEC Division of Enforcement Report indicated that over $\$ 3.7$ billion of penalties were assessed in 2017 and of these enforcement actions, $73 \%$ were attributable to only a few
}

Thus, increases in employee pornography consumption are likely to increase firm-level fraud risk and the risk of other self-serving behaviors that hinder achievement of organizational goals.

Second, because pornography consumption causes dehumanization of others, the incidence of sexual harassment or hostile work environments is likely to increase with increases in employee pornography consumption. This is detrimental to organizations because harassment imposes both direct costs on the company (e.g., from payouts to the U.S. Equal Employment Opportunity Commission (EEOC) and plaintiffs, attorney's fees) and indirect costs in terms of lost productivity and employee turnover. A 2016 report issued by the U.S. EEOC concludes that the indirect costs of lost productivity from harassment extends to all workers, not just those directly impacted, and that its true cost includes lost productivity, increased turnover, and damage to the firm's reputation.

Finally, our results are important because they are suggestive of other potential costs of pornography in addition to unethical behavior. Because pornography increases employees' propensity to dehumanize others, it also likely causes other negative outcomes that stem from dehumanization aside from unethical behavior. For example, dehumanization causes delegitimization (Bar-Tal 2000), which may be seen when an individual or group is delegitimized to prevent them from getting a promotion; aggression (Greitemeyer and McLatchie 2011; Rudman and Mescher 2012), which may be exhibited by verbal abuse of an employee by a manager; and unwillingness to help others (Andrighetto et al. 2014; Cuddy et al. 2007), which could have adverse effects especially in team projects. Given the negative effects of pornography we find in this study and that others have found (Malamuth and Ceniti 1986; Willoughby et al. 2014), it is important for business, political, and other leaders to consider the significant risks pornography poses to the achievement of organizational outcomes and respond accordingly.

\section{Literature Review}

Pornography is a broad term that encompasses many different facets. Because of its broad nature, we follow Negash et al. (2016) and define pornography as viewing any sexually explicit material. ${ }^{6}$ Over the last 25 years, the internet

\footnotetext{
Footnote 5 (continued)

individuals within a firm. Individuals commit fraud and individual unethical behavior increases fraud risk (https://www.sec.gov/files/ enforcement-annual-report-2017.pdf).

${ }^{6}$ As described later in the methodology section of our paper, we define pornography to participants as "Pornographic materials are videos, magazines, internet websites, images, books, etc. that describe people having sex, show clear pictures of nudity or people
} 
has increased access, affordability, and anonymity of pornography (Cooper et al. 2000). Psychologist term these vicissitudes the "triple-A" engine and note that they are the driving forces behind changes in pornography consumption because people can now access pornography from home or work, with anonymity, and at low (or no) cost (e.g., Cooper 1998; Cooper and Griffin-Shelley 2002). Not surprisingly, the consumption of pornographic materials has increased and is increasing successively with each new birth generation (Price et al. 2016; Wright 2013). Numerous commentaries report widespread use of pornography. For example, some note that nearly 30,000 users watch pornography every second on the internet (CNBC 2009; Ropelato 2014) and that porn sites receive more visitors than Netflix, Amazon, and Twitter combined (Huffington Post 2013; Negash et al. 2016). More conservative estimates suggest that pornography-related internet searches account for about $13 \%$ of worldwide internet traffic (Ogas and Gaddam 2012). Although it is difficult to estimate with precision trends in pornography consumption, one can confidently conclude that pornography consumption is common, and its use has increased in recent years (e.g., Ogas and Gaddam 2012; Price et al. 2016; Wright 2013).

Pornography consumption does not appear to be isolated to a small subset of society. Recent research examining pornography consumption suggests that at a minimum $27 \%$ of Americans between the ages of 18 and 89 have viewed pornography (Wright et al. 2014) and the rate of consumption is likely considerably higher for young adults. Carroll et al. (2008) report that $87 \%$ of young-adult males and $31 \%$ of young-adult females disclose some degree of pornography consumption. The high consumption of pornography and the rate of increase in its use have spurred significant academic interest, with many studies finding deleterious effects from viewing pornography. ${ }^{7}$

While prior research documents individual and relationship consequences of pornography consumption, the literature provides considerably less evidence on how pornography consumption influences organizations and society more broadly, including how it influences businesses. We

\footnotetext{
Footnote 6 (continued)

having sex, or show a movie or audio that describes people having sex."

7 We refer interested readers to summaries of the research on pornography (see Manning 2006, Owens et al. 2012, and Short et al. 2012). Prior research shows that pornography consumption lowers selfesteem (Willoughby et al. 2014), increases depression levels (Willoughby et al. 2014), creates unrealistic sexual expectations (McKee 2007a), and increases aggression (Malamuth and Ceniti 1986). Furthermore, pornography reduces relationship quality and increases infidelity (Maddox et al. 2011) and reduces women's self-esteem (Stewart and Szymanski 2012).
}

are unaware of any research that directly tests how pornography consumption influences unethical behavior. Rest (1986) defines unethical behavior as any organizational member action that violates widely accepted (societal) moral norms. This definition of unethical behavior has been used (and found descriptive) in a variety of contexts (Kaptein 2008; Kish-Gephart et al. 2010; Treviño et al. 2006); thus, we employ it as our definition of unethical behavior. In this study, we examine whether pornography consumption influences decision maker's tendency to behave unethically. More specifically, we examine if viewing pornography increases an individual's propensity to engage in unethical behavior, which we operationalize in two ways: (1) dishonestly abusing company policies and (2) shirking and lying about work performed. These are relevant unethical workplace behaviors; a recent survey on unethical workplace behavior reports that the five most common infractions include (1) misuse of company time, (2) abusive behavior, (3) employee theft, (4) lying, and (5) violating the company internet policy (Rodriguez 2015).

We looked to prior research to identify mechanisms that were (1) likely to intensify when consuming pornography, and (2) likely to increase unethical behavior. Prior research suggests at least two, non-mutually exclusive mechanisms for pornography consumption to influence unethical behavior: it may (1) encourage delay discounting and (2) intensify dehumanization of others (and therefore increase moral disengagement). ${ }^{8}$ Prior research posits that these mechanisms activate or intensify when viewing pornography, although, as discussed in the following sections, the evidence on the actual effect of pornography on each mechanism is nuanced. Delay discounting and dehumanization have also been linked to changes in unethical behavior. Thus, we examine the relation between pornography consumption and unethical behavior and explore whether delay discounting and dehumanization mediate the relation. In the following sections, we discuss each of these mechanisms and then present our formal hypotheses.

\section{Delay Discounting}

Delay discounting is discounting future outcomes or preferring an outcome today over a more valuable future outcome (Lawyer 2008; Negash et al. 2016; Rachlin and Green 1972). Individuals who are willing to accept more valuable future rewards than less valuable immediate rewards have lower discount rates (i.e., outcomes lose less value over time), whereas individuals who prefer immediate gratification over

\footnotetext{
${ }^{8}$ See for example Lawyer (2008), Negash et al. (2016), Peter and Valkenburg (2007), Van den Bergh et al. (2008), and Wilson and Daly (2004).
} 
larger future rewards are described as having higher discount rates. As an example, someone with a high delay discounting rate would rather receive $\$ 1$ now than $\$ 10$ a week from now, whereas a person with a lower delay discounting rate would wait the week to receive the larger amount.

Individuals who have high discount rates are described as "impatient, impulsive, short-sighted, or lacking in selfcontrol" (Fawcett et al. 2012, p. 128). Higher levels of delay discounting are associated with behaviors such as addictions, impulsive decision making, substance abuse, risky sexual behavior, obesity, internet addiction, criminal behavior and excessive gambling (Buzzell et al. 2006; Chesson et al. 2006; Crean et al. 2000; Davis et al. 2010; Dixon et al. 2006; Lee et al. 2017; MacKillop 2013; Romer et al. 2010; Saville et al. 2010). That is, delay discounting is a strong predictor of short-sighted behavior including unethical behavior. Lee et al. (2017) also find that increases in crime are associated with increases in delay discounting suggesting that not only do individuals with greater delay discounts behave unethically but behaving unethically also increases delay discounting. Research has also linked pornography consumption to increases in delay discounting using both laboratory experiments and data collected from the field (Lawyer 2008; Negash et al. 2016; Van den Bergh et al. 2008; Wilson and Daly 2004).

Taken together, the research suggests that pornography consumption is associated with greater delay discounting and greater delay discounting is associated with unethical behavior. This suggests that pornography consumption will cause increases in unethical behavior because of increases in delay discounting. Increases in employees' propensity to more heavily discount future outcomes relative to short-term benefits have the potential to influence numerous unethical decisions made by employees. For example, accountants decide about "massaging" the financial statement numbers to look good immediately, often to gain higher bonuses or increase the value of their equity-based compensation, at the expense of longer-term firm value (Bergstresser and Philippon 2006; Cohen et al. 2008; Graham et al. 2005; Holderness et al. 2018). Managers often must weigh the long-term benefits associated with complying with costly environmental regulations against the short-term payoff to non-compliance. Similarly, managers may gain short-term rewards from insider trading that impose long-term cost on the manager (and even the firm). As such, increases in delay discounting from employee consumption of pornography could negatively influence numerous organizational decisions. Likewise, higher discount rates and impulsivity may lead to unethical customer behavior such as shoplifting.

\section{Dehumanization}

Moral self-regulation is one mechanism that individuals use to ensure that their behavior corresponds to ethical standards (Bandura 1999). The self-regulation process, however, can be activated or ignored (Bandura 1999; Detert et al. 2008). Moral disengagement is the term used to describe failing to activate (or ignoring) moral self-regulation. Failing to activate moral self-regulation via moral disengagement increases unethical behavior (e.g., Bandura 1991, 1999; Detert et al. 2008; Gabbiadini et al. 2014). Bandura's (1986) model of moral disengagement includes eight mechanisms that lead to moral disengagement of which one is dehumanization. ${ }^{9}$

Dehumanization is the psychological process of viewing and treating others like objects or as a means to an end rather than as humans (Papadaki 2010; Saul 2006).${ }^{10}$ High levels of dehumanizing acts occur in the most popular pornographic material (Bridges et al. 2010 Klaassen and Peter 2015; McKee 2005) and thus it is a commonly held belief that pornography increases dehumanization. Hence, we focus on dehumanization as the likely path to moral disengagement from pornography consumption. Moreover, research indicates that dehumanization is an "everyday social phenomenon" that is influenced by situational factors (Haslam 2006, 937) and does not require an "in" and "out" group but can occur as an individual phenomenon (Haslam et al. 2005).

While it is a commonly held belief that the dehumanizing acts in pornography increase pornography viewers' tendency to dehumanize people, especially women, (Fagan 2009; Schneider 2000), most evidence is only correlational, not casual. For example, Peter and Valkenburg (2007) find an association between exposure to pornography and dehumanization of women; the authors note, however, that this relation could occur because pornography encourages dehumanization or because viewers who hold women in low regard are more likely to consume pornography. Complicating the issue further is the mixed correlational evidence. McKee (2007b) found that there was no relationship between pornography consumers' attitudes toward women and the amount of pornography consumed. Using survey evidence, Hald and Malamuth (2008) report that pornography has a positive influence on men's perception of women.

Ward (2002) is an exception that uses an experimental design to examine the causal relation between stereotypes

\footnotetext{
9 The other seven mechanisms are moral justification, euphemistic labeling, advantageous comparison, displacement of responsibility, diffusion of responsibility, disregarding the consequences, and attribution of blame.

${ }^{10}$ Several other terms are often used that are closely related to dehumanization including objectification, degradation, and domination (McKee 2005).
} 
depicted in media and teenagers' attitudes and assumptions about those depicted in the media content. She finds a casual relation between media dehumanizing women and viewers beliefs that women are sex objects. Ward and Friedman (2006) find similar evidence. The results in both studies are obtained from media that would not be classified as pornography (e.g., clips from television shows such as Friends and Seinfeld), but one might expect that the results would also obtain for pornographic media and that the relation might even be stronger.

In summary, although pornography tends to include dehumanizing acts, the correlational evidence on the relation between pornography and dehumanization is mixed and the experimental evidence on the relation between media that reflects common stereotypes and viewers' attitudes about women does not examine pornographic media. Thus, there is some uncertainty as to whether pornography does increase levels of dehumanization. With this study, we hope to add to the literature on pornography by providing experimental evidence on the causal relationship between viewing pornography and dehumanization and, in turn, whether dehumanization caused by viewing pornography increases unethical behavior.

Increases in unethical behavior from dehumanization have the potential to manifest in numerous business contexts. For example, an increased tendency to lie to obtain gain and to view others only as a means to an end is likely to be highly detrimental to team effectiveness and cooperation within an organization (Moore et al. 2012). Cooperation and trust across functional areas of expertise are often necessary to achieve important firm goals (e.g., developing new products, entering new markets, increasing customer satisfaction). As such, a substantial decrease in trust and cooperation from increased employee dehumanization of others has the potential to negatively impact firm-level outcomes. In addition, in recent years organizations have made large investments in programs aimed at retaining and developing talented women. ${ }^{11}$ These investments may be severely undermined when employees, particularly those in leadership positions, consume pornography. Related, increased employee propensity to dehumanize co-workers is likely to increase the incidence of sexual harassment or hostile work environments, both of which can decrease firm productivity and lead to costly litigation.

Finally, dehumanization can also affect the customer-firm relationship. Employees treating customers like objects rather than respecting their innate value as an individual

\footnotetext{
$\overline{11}$ For example, in 2015 Google, Intel, and Apple had set aside $\$ 500$ million for diversity hiring, which includes hiring women (Guynn 2015). In addition, as of 2017 , over 70 companies had publicly announced targets they have for increasing the number of female workers (Huang 2017).
}

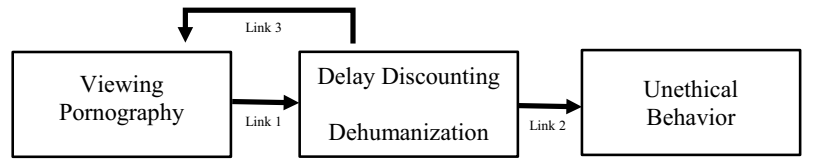

Fig. 1 Model of unethical behavior. This figure illustrates our predictions (links 1 and 2) and the likely selection effect that occurs if people more likely to dehumanize others are also more likely to view pornography (link 3). Our experimental design allows us to test links 1 and 2 because random assignment results in less ethical people being equally represented in both experimental conditions. Thus, selection effects cannot account for our results. Although link 3 is interesting, we do not explore it as it is outside of the scope of our analyses. Nonetheless, for completeness, we included it in our model of unethical behavior

is likely to reduce customer retention and may even generate negative online or media attention. On the other hand, customers can dehumanize firms by viewing a firm as a non-human entity rather than as a collection of individuals. For example, a customer who makes a fraudulent return can dehumanize the employees of a firm by thinking that they are only decreasing the firm's profit but are not hurting any people. By viewing the firm as an object rather than a collection of individuals, a customer places the firm between themselves and the employees of the firm, who are ultimately affected by a customer's unethical behavior. This perspective decreases the psychological proximity a customer feels toward those who are affected by the customer's behavior and is likely to increase unethical customer behavior (Jones 1991). ${ }^{12}$

\section{Hypotheses}

The preceding discussion leads to our first hypothesis about the relation between viewing pornography and unethical behavior and our second, two-part hypothesis about the mechanisms by which pornography causes unethical behavior. Stated formally:

H1: Consuming pornography increases unethical behavior.

H2a: Consuming pornography increases delay discounting, which increases unethical behavior.

\footnotetext{
12 Psychological proximity refers to the nearness a person has for an object or person (Trope and Liberman 2010). In Jones' (1991) model of moral intensity, it specifically refers to the closeness a moral agent feels to those affected by an ethical decision. Jones (1991) argues a positive relationship between proximity and moral intensity and that as moral intensity increases, ethical behavior will occur more frequently. Prior research has shown the existence of a negative relationship between proximity and unethical behavior (Watley and May 2004; Yam and Reynolds 2016).
} 
H2b: Consuming pornography increases dehumanization, which increases unethical behavior.

Figure 1 illustrates our predictions that consuming pornography increases delay discounting and dehumanization (link 1), and that pornography-induced delay discounting and dehumanization increase unethical behavior (link 2). The figure also illustrates the likely selection effect that occurs; people more likely to dehumanize others are also more likely to view pornography (link 3 ). Our experimental design allows us to test links 1 and 2 while controlling for link 3; random assignment results in less ethical people being equally represented ${ }^{13}$ in both experimental conditions thereby allowing us to control for differences across people in their tendency to discount future events and dehumanize others. $^{14}$

\section{Survey Design and Results}

We gather evidence using two complementary methodologies. First, we use a survey designed to reflect a nationally representative sample to provide an associative test of $\mathrm{H} 1$ and to provide strong external validity that our results generalize to a large population. The survey examines if a general relation between pornography consumption and unethical behavior is evident in the population. We understand, however, that this methodology is limited in that the results may be attributable to correlated omitted variables or the endogeneity of the choice to consume pornography and the choice to behave unethically. Thus, we use a second methodology, a randomized experiment, that is not subject to these limitations and allows us to examine if delay discounting and/or dehumanization are mediating variables. That is, the randomized experiment provides stronger internal validity and facilitates tests of our mediating hypotheses. The survey results are presented in the next section and the experimental results follow.

\footnotetext{
13 While we do not have a pre-treatment measure of ethicality, we find no difference between the two conditions in age, marital status, education, employment status (working or not), income level and self-reported use of pornography. Thus, we have no reason to believe that randomization was not successful in randomly assigning less ethical people equally across the two conditions.

14 Although link 3 is interesting, we do not explore it as it is outside of the scope of our analyses. Nonetheless, for completeness, we included it in our model of unethical behavior and encourage future research to probe this link further.
}

\section{Survey Design}

\section{Participants}

We paid Qualtrics to recruit a panel of 1000 adult participants-they returned 1083 usable responses. Qualtrics used quota filters to generate a sample reflective of the U.S. national population in demographics. ${ }^{15}$ In terms of demographics, $48.5 \%$ of the sample were male, and the average age was 47 . Approximately $43 \%$ of the sample had a bachelor's degree or higher, and $24 \%$ had received only a high school degree or less. The selection of a near nationally representative sample allows us to infer that these results should generalize to the U.S. adult population.

\section{Task and Measures}

The survey first asked participants demographic questions and then participants read the following scenario:

You recently purchased an expensive chair at a local store that has a strict return policy. The return policy allows you to return items if there was a defect in manufacturing but not if you caused damage to the product through misuse. Although you know the store has a strict policy, you also know that the only way they enforce the policy is by asking the customer whether they misused the product or not. After you brought the chair home, you damaged it through your own misuse so that it is no longer functional.

After reading the situation, participants indicated how likely they would be to return the product and claim that it had a defect in manufacturing so they could receive a new chair. Responses were recorded on a 5-point scale consisting of definitely would not return (1), probably would not return (2), maybe would return (3), probably would return (4), and definitely would return (5). Participants then indicated how often they viewed pornographic materials. We defined pornographic material for participants as "videos, magazines, internet websites, images, books, etc. that describe people having sex, show clear pictures of nudity or people having sex, or show a movie or audio that describes people having sex." Participants responded on a 5-point scale labeled: never (1), rarely (2), occasionally (3), frequently (4), or very frequently (5). We examine a customer-based situation because, like employees, customers are important

\footnotetext{
15 The panel completed data for this study and for another, unrelated study, which focused on political beliefs. The political beliefs experiment was conducted first. We tested for differences in our study based on the different manipulations in the other experiment and found that it had no effect on any of our measures.
} 


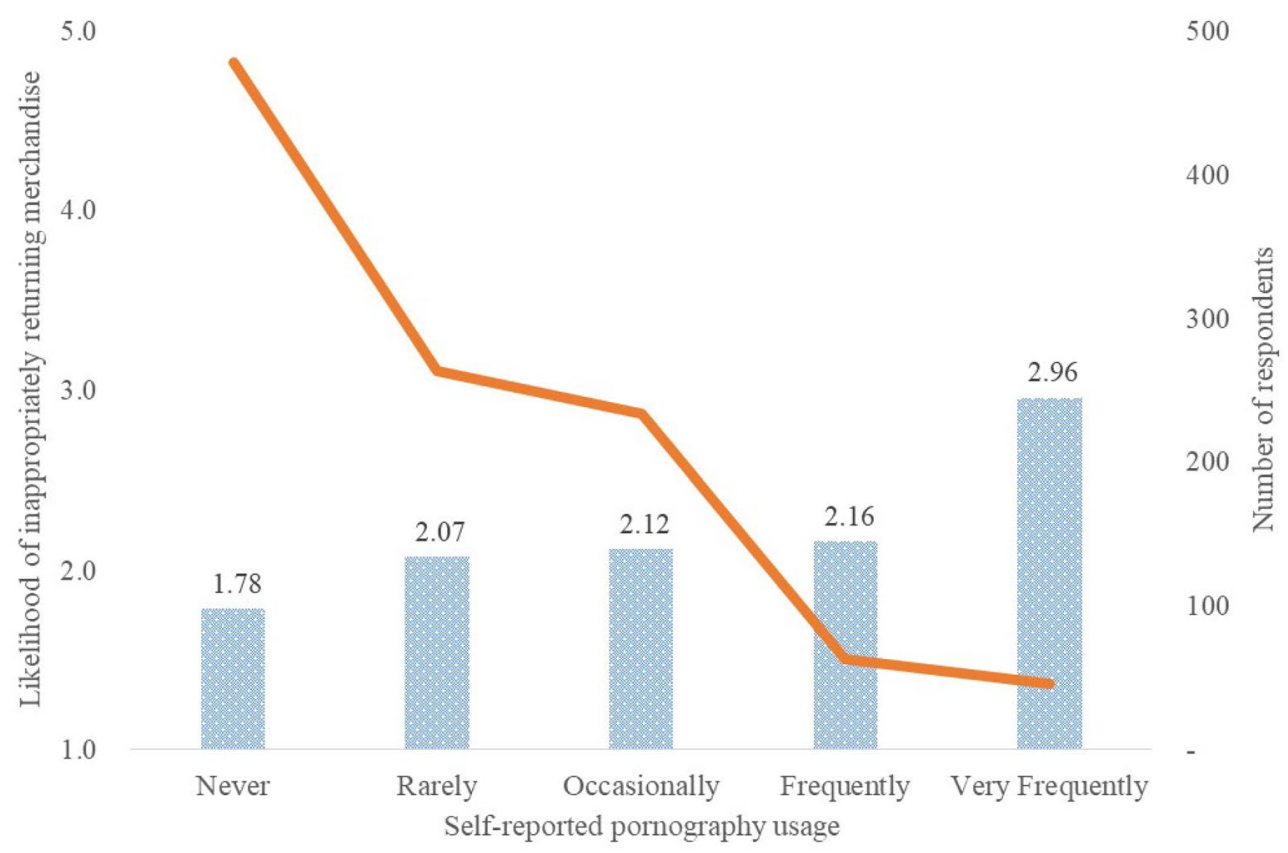

Likelihood of inappropriately returning merchandise $\quad$ Number of respondents

Fig. 2 Effects of self-reported pornography usage on unethical behavior using the survey data. This figure illustrates the results taken from a nationally representative sample (i.e., the survey data). The figure shows on the left $y$-axis the likelihood of dishonestly returning mer-

stakeholders in business (Ferrell 2004; Henriques and Sadorsky 1999).

\section{Survey Results}

Figure 2 and Table 1 present the results examining the correlation between survey participants' willingness to dishonestly return the chair and pornography consumption. A statistically significant positive (negative) relationship suggests that pornography consumption is associated with increases (decreases) in dishonest behavior. Figure 2 illustrates a positive relation between frequency of pornography consumption and unethical behavior. Table 1, Panel A provides the distribution of how often people report viewing pornography. We find that $44 \%$ of the sample never view pornography, $24 \%$ rarely view it, $22 \%$ occasionally view it, and $6 \%$ and $4 \%$ frequently and very frequently view pornography, respectively. ${ }^{16}$ Thus, $56 \%$ of the nationally representative

\footnotetext{
$\overline{16}$ Regnerus et al. (2016) reports comparable percentages. Also, in untabulated analysis we examine statistics by gender and note that $44 \%$ of men routinely view pornography (i.e., view it occasionally, frequently or very frequently). The corresponding statistic for women in our sample is $20 \%$. The gender-partitioned statistics in Regnerus et al. (2016) are comparable to our statistics (i.e., $46 \%$ of men and $16 \%$ of women regularly view pornography in their study).
}

chandise to a store and on the $x$-axis participants self-reported usage of pornography. The right $y$-axis and the line show the number of participants who reported pornography consumption in each category

sample indicate at least some propensity toward pornography consumption. Furthermore, we see a monotonically increasing relation between self-reported pornography consumption and willingness to unethically return the item to the store. An ANOVA using contrasts shows three distinct groups (results not tabulated). The participants that never view pornography are statistically less likely to be unethical than all other participants. The participants who report frequent viewing pornography are significantly more unethical than all other groups. The participants that rarely, occasionally, and frequently view pornography are significantly more likely to return the item than the participants who never view pornography but significantly less likely to return the item than the participants who report viewing pornography very frequently.

Next, we examine the relation between participants willingness to dishonestly return the chair and pornography consumption in a regression model that includes several control variables to reduce the likelihood that our results are attributable to correlated omitted variables. Specifically, we include age because prior research shows that younger people are more likely to consume pornography (Buzzell 2005; Hald 2006), gender as men are more likely to view pornography than women (Buzzell 2005; Cooper et al. 2000; Hald 2006), education as less educated individuals consume more pornography than more educated individuals (Richters et al. 
Table 1 Analysis of survey data

Panel A: Average willingness to dishonestly return item by frequency of porn viewing

\begin{tabular}{lllll}
\hline Frequency of porn viewing & $N$ & $\%$ & Dishonestly return item & SD \\
\hline 1-Never & 478 & 44 & 1.78 & 2.07 \\
2-Rarely & 263 & 24 & 2.12 & 1.15 \\
3-Occasionally & 233 & 22 & 2.16 & 1.15 \\
4-Frequently & 63 & 6 & 2.96 & 1.18 \\
5-Very frequently & 46 & 4 & 1.71 \\
\hline
\end{tabular}

Panel B: Regression results, dependent variable willingness to dishonestly return item

\begin{tabular}{lccrr}
\hline Variable & Coefficient & SE & Wald $\chi^{2}$ & $p$ value \\
\hline PornViewing & 0.19 & 0.06 & 11.70 & 9.72 \\
Age & -0.01 & 0.00 & 0.11 & 0.002 \\
Male & 0.04 & 0.13 & 1.56 & 0.738 \\
Educated & -0.05 & 0.04 & 33.38 & $<0.212$ \\
Aggression & -0.30 & 0.05 & &
\end{tabular}

This table presents the results taken from a nationally representative sample. Panel A reports the average score Dishonestly Return Item by self-reported frequency of pornography consumption habits, while Panel B reports the results of an ordered logistic regression of Dishonestly Return Item on frequency of pornography consumption (PornViewing) and control variables. An ordered logistic regression is used because the dependent variable reflects ordinal rather than interval data. The dependent variable (Dishonestly Return Item) was measured on a 5-point scale consisting of definitely would not return (1), probably would not return (2), maybe would return (3), probably would return (4), and definitely would return (5). Variables are defined as follows: PornViewing is the frequency that an individual viewed pornography, measured on a 5-point scale. Age is the Age of the individual measured in years. Male is a dichotomous variable taking the value of 1 if the individual was male and a value of 0 otherwise. Educated is a categorical variable measuring level of education consisting of less than high school degree (1), high school/ GED (2), some college (3), 2-year college degree (4), 4-year college degree (5), master's degree (6), doctoral degree (7), and professional degree (8). Aggression is the trait aggression measured using the short form (12 questions) of the Buss-Perry Aggression Questionnaire. Higher values indicate more aggression

2003, Yang 2016), and aggression because prior research shows that more aggressive individuals may be more likely to consume pornography (Malamuth et al. 2012). We report the results from this analysis in Panel B of Table 1. We find that even after controlling for these variables, pornography consumption is positively associated with unethical behavior. We conduct additional analyses and do not find evidence that any of the control variables interact with self-reported pornography consumption to effect unethical behavior. Thus, our survey evidence testing H1 suggests that viewing pornography is positively associated with unethical behavior.

\section{Experimental Design and Results}

\section{Experimental Design}

\section{Participants}

We employed 200 participants for an experiment using Amazon's online labor market Mechanical Turk (MTurk). One hundred and ninety-nine successfully completed the task. In terms of demographics, $54 \%$ of the sample were male, the average age was 35 years old, and $91 \%$ of the sample were employed aside from working for MTurk. We used the MTurk labor market for several reasons. First, it provides a real-world setting for our experiment. Participants were hired and paid for completing a task that they would reasonably be expected to perform on MTurk. Second, while not explicitly being a representative sample, MTurk participants respond similarly to large random samples of U.S. participants in traditional experiments (Berinsky et al. 2012; Paolacci and Chandler 2014). Third, research has shown that MTurk users respond to incentives to cheat but are no more likely to cheat than college students, and they are truthful when self-reporting demographics (Goodman et al. 2013; Suri et al. 2011). ${ }^{17}$

\section{Task and Measure}

We informed participants that we were employing them to participate in a study of how memory specificity affects

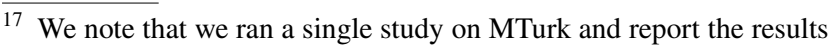
for all participants for which we obtained complete data. Participants took an average of $22.7 \mathrm{~min}$ to complete the task and were paid $\$ 2.00$ for participating.
} 
media perceptions. We noted in bold that participants were being paid to watch a video in its entirety. The participants then performed a memory task, which asked them to recall two events and describe them in detail. The first recall experience asked all participants to describe in detail their last birthday. Participants were then randomly assigned to be in either a control condition or the pornography condition. For the second recall experience, those assigned to the control condition described their last experience exercising, including their clothing, exercises performed, and the setting. In contrast, participants in the pornography condition were asked to describe their last experience viewing pornography, including the medium viewed, content, and the length of time.

We intentionally chose not to expose participants to pornographic material for several reasons. First, we did not want to tell participants before the study that it might contain pornographic material as this could create selection effects and/ or demand effects. Second, if we did not tell participants that the study could contain pornographic materials it would be unethical to force participants to view material that some find objectionable (and may even cause participants harm). Third, our method allows participants to indicate no use of pornography and not cause them harm while also activating pornographic imagery in the minds of participants who consume pornography. Thus, we achieved the desired effect of activating pornographic imagery in the minds of participants and avoided undesired exposure to pornography.

After describing their memories, we asked all participants to watch a 10-min movie clip from Blue by Derek Jarman. The video consisted of a blue background with a monotone voice speaking and subtitles for the entire $10 \mathrm{~min}$. The clip was purposely boring and lengthy to provide an incentive for participants to skip the movie. After watching the video, participants briefly described their reactions to the movie clip. ${ }^{18}$

Following the video portion of the experiment, participants provided responses to measure delay discounting and dehumanization in order to test for mediation effects (measurement order was randomized). ${ }^{19}$ Delay discounting was measured using the method suggested by Kirby and Maraković (1996) (see "Appendix 1" section for the questions). Participants were presented with different situations

\footnotetext{
18 We note this task has been successful at measuring ethical decision making in another study (e.g., see Gubler et al. 2018).

19 We have two measures for the dependent variable, whether the participant shirked work (i.e., did not watch the full video) and whether they lied about it. We collect process measures after the first measure of the dependent variable but before the second. The two measures for the dependent variable are $100 \%$ correlated (i.e., all participants who skipped watching the video also lied about watching the video). Thus, the point at which we asked the processes measure does not appear to have any effect on the ethical behavior of the participants.
}

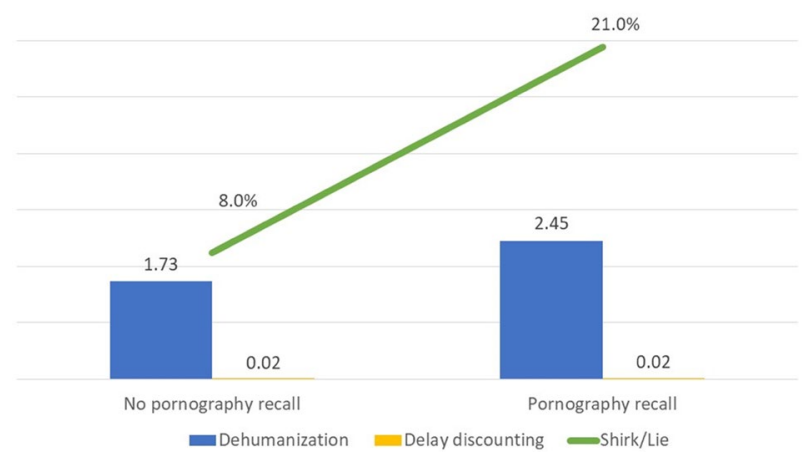

Fig. 3 Effects of recalling pornography on unethical behavior and possible mediators using the experimental data. This figure illustrates the results from the experimental data. The figure shows the percentage of participants that shirked and lied about work performed when recalling pornography. It also shows the averages for the two possible mediators, dehumanization, and delay discounting across the two experimental conditions

and were instructed to choose the reward they prefer, which was either an immediate reward or a larger delayed reward. The output of this scale represents the discount rate at which a participant switches from choosing an immediate reward to choosing the delayed reward. Dehumanization was measured using a method used in Leyens et al. (2001) that has participants designate to what extent they perceive others to be capable of having secondary emotions (see "Appendix 2" section for the questions). ${ }^{20}$ Participants who view others as less capable of having secondary emotions are classified as having greater tendencies to dehumanize others.

Finally, participants were asked if they watched the movie clip in its entirety. Because we were able to record how long each participant viewed the movie clip, we identified those participants who watched the entire video and those who did not. To measure lying, we identified those participants who did not watch the entire video but answered that they had. That is, we create dichotomous variable indicating whether participants lied or did not lie. In no instance did a participant skip portions of the movie clip and report honestly that they did not watch the entire clip. Thus, in our experiment, shirking and lying about work performed were used concurrently every time a participant shirked.

Participants then reported how often they viewed pornographic material. Pornographic materials were described to the participants using the same definition as was used in the survey. Participants were also asked questions about personality and religiosity.

\footnotetext{
${ }^{20}$ We computed Cronbach's alpha for the four secondary emotions used to compute the dehumanization measure and it has an "excellent" score of 0.908 (Kline 2000).
} 
Table 2 Analysis of experimental data

\begin{tabular}{lllllll}
\hline Variable & $\begin{array}{l}\text { No Pornog- } \\
\text { raphy Recall }\end{array}$ & & \multicolumn{2}{l}{ Pornography } & Tests for differences \\
\cline { 2 - 3 } & Mean & SD & & Mean & SD & \\
\hline Shirk/lie & 0.08 & 0.28 & & 0.21 & 0.41 & $\chi^{2}=6.08, p=0.007$ \\
Delay discounting & 0.02 & 0.03 & & 0.02 & 0.02 & $t=1.10, p=0.274$ \\
Dehumanization & 1.73 & 0.95 & & 2.45 & 1.75 & $t=-3.64, p<0.001$ \\
\hline
\end{tabular}

199 participants completed the task. The No Pornography Recall condition had 97 participants and the Pornography Recall condition had 102 participants. Comparisons are made between two groups: the No Pornography Recall group did not recall their most recent experience viewing pornography and the Pornography Recall group recalled their most recent time viewing pornography. Variables are defined as follows: Shirk/lie is a dichotomous variable taking the value of 1 if the participant skipped the video (i.e., shirked work) and lied about watching the video and 0 otherwise. Delay discounting is the questions based on Kirby and Maraković (1996). Participants indicated whether they would take an immediate reward or delayed award for 21 different scenarios. Responses are then coded so that higher values indicate greater delay discounting. Dehumanization is the infrahumanization scale developed by Leyens et al. (2001). We averaged the 7-point scale responses for the four secondary emotions and code them so that higher values indicate more dehumanization

\section{Experimental Results}

We report the results testing our hypotheses using an experiment in Fig. 3 and Table 2. Figure 3 provides a visual representation of the results and shows that respondents in the pornography recall condition shirked and lied about work performed more than respondents who recalled non-pornographic material. Table 2 shows that $21 \%$ of participants who were asked to recall viewing pornography did not watch the video and lied about the work they performed compared to only $8 \%$ of participants who recalled a non-pornographic event. This difference is statistically significant and large in magnitude as it is a $163 \%$ increase in shirking/lying. Thus, these experimental results support the survey results and provide stronger causal evidence that viewing pornography causes individuals to be less ethical.

When comparing possible mediators across conditions, we observe that only dehumanization is statistically significant across the two conditions (see Fig. 3 and Table 2). ${ }^{21}$

\footnotetext{
${ }^{21}$ We use the dehumanization scale from Gubler et al. (2018). Although not reported in their study, the authors communicated to us that the mean value of the dehumanization in Gubler et al. (2018) is 2.12 which is similar to the mean value in our study of 2.10 . Although the mean amount of 2.10 is low, there was significant variation and the mean is significantly greater than the bottom of the scale suggesting a floor effect is not a concern. The low mean values indicates that most people think others are "very likely" to not experience secondary emotions. What is more important than the mean value of this variable is that there are differences between conditions, which shows that our manipulation caused an increase in dehumanization.
}

That is, the group that recalled pornography was more likely to dehumanize others than the group that did not recall pornography. The group that recalled pornography did not experience more delay discounting. ${ }^{22}$

To formally test $\mathrm{H} 2$, we conduct a mediation analysis using Andrew Hayes' Process Macro for SAS. In Table 3, we report the results from the test of the two different models and find that the only model where we observe a significant indirect effect of pornography on shirking work and lying is dehumanization. ${ }^{23}$ Thus, we conclude that the reason pornography increases unethical behavior is that viewing pornography causes the viewer to dehumanize others, which in turn leads to the viewer being more willing to shirk work and lie to get gain.

Although we randomly assigned participants to conditions, it is possible that, by chance, the conditions differ on important dimensions that could influence the results. Thus, we test whether our conditions differed on demographic variables or other variables that may influence the results. Specifically, we tested whether the conditions were similar in terms of gender, age, marital status, education, employment status (working or not), income level, self-reported use of pornography, and self-reported religiosity. We found that randomization was successful in that there were no statistically significant differences between conditions except for self-reported religiosity-specifically, the condition that recalled pornography had more religious people than the control condition (which should bias against finding results; results not tabulated). Therefore, we conduct an ANCOVA to compare whether our results are robust to including our measure of religiosity. We find that the results are robust to the inclusion of religiosity as a covariate. Furthermore, we also test whether our results are robust to the inclusion of the other demographic variables as covariates (results not tabulated); we find that our results are robust.

Finally, it is possible that participants assigned to the pornography condition do not view pornographic material. If the individuals who refrain from pornography are less likely to lie as we hypothesize, this would bias against finding results. Nevertheless, we examine the participants' descriptions or their pornography consumption and we found that

\footnotetext{
22 The value of the delay discounting scale represents the discount rate at which participants switched from choosing the immediate reward to the delayed reward (Kirby and Maraković 1996). Thus, higher values represent a desire for more immediate rewards. We note that the average discount rate we report $(0.02)$ is higher than the average rate found in Kirby and Maraković (1996) (0.007). This difference may be due to generational differences as our study was conducted more than 20 years after Kirby and Maraković (1996).

${ }^{23}$ In terms of model fit for the dehumanization model, the adjusted $R^{2}$ values for the regressions of Lying on Recall Pornography is 0.026, of Lying on Dehumanization is 0.075, and of Lying on Recall Pornography and Dehumanization is 0.082 .
} 
Table 3 Analysis of possible mediating relationships for experimental data

Panel A: Mediation Models for Testing

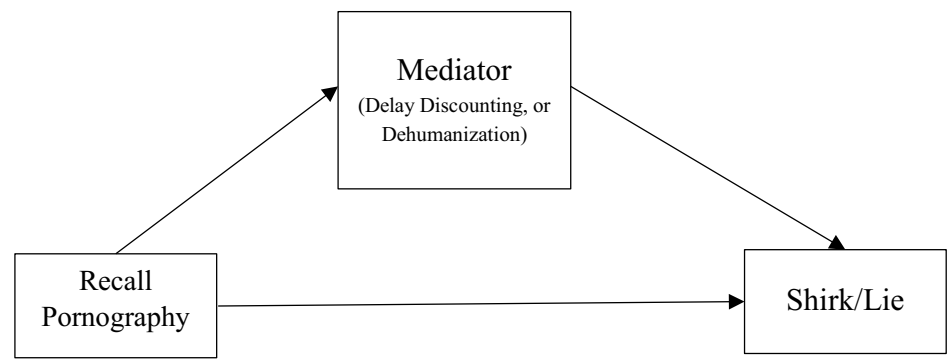

Panel B: Mediation Testing Results for Indirect Effects

$\begin{array}{llccc}\text { Possible Mediator } & \text { Effect } & \text { Effect } & \mathbf{Z} & \text { P-value } \\ \text { Delay Discounting } & \begin{array}{l}\text { Indirect Effect of Pornography on } \\ \text { Shirking/Lying }\end{array} & -0.02 & -0.41 & 0.683 \\ \text { Dehumanization } & \begin{array}{l}\text { Indirect Effect of Pornography on } \\ \text { Shirking/Lying }\end{array} & 0.27 & 2.27 & 0.023\end{array}$

Panel A illustrates the mediation model. In Panel B, unstandardized effect sizes of indirect effects, z-values, and p-values are presented for each possible mediator. The Andrew Hayes Process Macro for SAS was used to compute the three different possible mediation models (using logistic regression where appropriate). See Table 2 for variable descriptions.

18 respondents $(17.7 \%$ of the sample) reported never viewing pornography in their description, 14 respondents (13.7\% of the sample) report inadvertently viewing pornography, and the remaining 70 respondents $(68.6 \%$ of the sample) described in detail viewing pornography. ${ }^{24} \mathrm{We}$ re-ran our analyses in three ways: (1) excluding those who reported never viewing pornography, (2) excluding those who reported inadvertently viewing pornography, and (3) excluding those who reported never or inadvertently viewing

\footnotetext{
$\overline{{ }^{24} \text { Examples }}$ of those who report not viewing pornography include "I do not view pornography" or "I do not watch pornography. Watching it conflicts with my beliefs." Examples of those who view pornography when shown by others include "There was a video on Facebook which looked like pornography. I was shocked and didn't believe it was pornography so I clicked on it. It was a porn from a popular website showing them have sex. I only viewed it for a few seconds because I don't watch pornography" or "The last time I viewed pornography was by accident, when I saw pornographic content posted to my dashboard. I didn't intend to see it, and the material was unattractive. I scrolled past it." Examples of those who described pornography include "A few days ago I opened a folder on my pc that is a collection of nude photos. I find it erotic to browse nudes of normal looking women of differing ages. I spent roughly 10 minutes" or "I looked at comic porn for about an hour. I looked at straight sex, monster sex, those involving known cartoon characters and lesbian sex. They weren't videos or pictures but comics online. I looked at them on my phone."
}

pornography. In all three analyses, our results are qualitatively similar to those reported. ${ }^{25}$

\section{Additional Descriptive Analysis}

We gather data on self-reported pornography consumption from both our survey and our experiment. In this section, we provide a descriptive analysis of factors associated with greater self-reported pornography consumption. This analysis may be useful to future researchers seeking to understand more about the use and the effects of pornography. Table 4 presents the results with Panel A reporting the results for the regression using the survey data and Panel $\mathrm{B}$ reporting the results for the regression using the experimental data. We did not ask the same demographic questions in both data collection efforts; thus, the models differ based on data availability.

The results from the survey data (Panel A) show that men are more likely to consume pornography than women, but pornography consumption decreases with age and Republicans are less likely to view pornography than those who

\footnotetext{
${ }^{25}$ We also test whether participants in the pornography recall condition who do not view pornography were more likely to lie than participants in the no pornography recall condition. The results show that there is no significant differences between these two groups ( $p$ value $>0.10)$.
} 
Table 4 Exploratory analysis of self-reported pornography use for survey and for experimental data

\begin{tabular}{|c|c|c|c|c|}
\hline Variable & Coefficient & SE & $t$ value & $p$ value \\
\hline \multicolumn{5}{|c|}{$\begin{array}{l}\text { Panel A: Ordered logistic regression with survey data, dependent } \\
\text { variable self-reported pornography consumption }\end{array}$} \\
\hline Male & 1.55 & 0.13 & 149.93 & $<0.001$ \\
\hline Age & -0.04 & 0.00 & 98.78 & $<0.001$ \\
\hline Education & 0.06 & 0.04 & 2.70 & 0.100 \\
\hline Republican & -0.26 & 0.15 & 3.08 & 0.079 \\
\hline Democrat & 0.07 & 0.14 & 0.23 & 0.633 \\
\hline \multicolumn{5}{|c|}{$N=1083 ;$ Pseudo $R^{2}=0.191$} \\
\hline \multicolumn{5}{|c|}{$\begin{array}{l}\text { Panel B: Ordered logistic regression with experimental data, } \\
\text { dependent variable self-reported pornography consumption }\end{array}$} \\
\hline Male & 1.31 & 0.29 & 20.50 & $<0.001$ \\
\hline Age & -0.02 & 0.01 & 1.33 & 0.249 \\
\hline Married & -0.47 & 0.29 & 2.51 & 0.113 \\
\hline Education & -0.25 & 0.12 & 4.31 & 0.038 \\
\hline Income & 0.00 & 0.00 & 6.09 & 0.014 \\
\hline Employed & 0.93 & 0.48 & 3.75 & 0.053 \\
\hline Religiosity & -0.52 & 0.14 & 14.89 & $<0.001$ \\
\hline \multicolumn{5}{|c|}{$N=195 ;$ Pseudo $R^{2}=0.269$} \\
\hline
\end{tabular}

This table reports the results from the ordered logistic regressions used for the exploratory analysis. An ordered logistic regression is used because the dependent variable reflects ordinal rather than interval data. The variables are defined as follows: Age is the age of the individual measured in years. Male is a dichotomous variable taking the value of 1 if the individual was male and a value of 0 otherwise. Education is a categorical variable measuring level of education consisting of less than high school degree (1), high school/GED (2), some college (3), 2-year college degree (4), 4-year college degree (5), master's degree (6), doctoral degree (7), and Professional degree (8). Republican is a dichotomous variable taking the value of 1 if the individual belonged to the Republican Party and a value of 0 otherwise. Democrat is a dichotomous variable taking the value of 1 if the individual belonged to the Democrat party and a value of 0 otherwise. Married is a dichotomous variable taking the value of 1 if the individual was married and a value of 0 otherwise. Income is a variable measuring self-reported level of income. Employed is a dichotomous variable taking the value of 1 if the individual was employed and a value of 0 otherwise. Religiosity is the average of two questions: "How often do you attend church or other religious meetings?" and "How often do you spend time in private religious activities, such as prayer, meditation, or Bible study?" Higher values indicate greater religiosity

do not belong to one of the two main political parties (an F-test also reveals that Republicans view pornography less frequently than Democrats). The results from the experimental data (Panel B) show that men, wealthy individuals, and employed individuals are more likely to view pornography but educated and religious individuals are less likely to view pornography. It comes as no surprise that our results are consistent with previous studies that identify young individuals, employed individuals, and men as more likely to view pornography (Buzzell 2005; Cooper et al. 2000; Hald 2006). Our result showing religious individuals are less likely to view pornography is consistent with Short et al. (2015), which show that religious individuals are less likely to ever or currently view pornography and is somewhat consistent with Baltazar et al. (2010), which show that religiosity is correlated with fewer hours spent viewing pornography in males. Our results are also consistent with Richters et al. (2003) and Yang (2016) which show that education is negatively associated with viewing pornography. However, our results concerning income are inconsistent with Buzzell (2005) who find that there is a negative relationship between viewing pornography and family income. ${ }^{26}$

\section{Conclusion}

In this study, we find evidence that viewing pornography affects unethical behavior. Using an experiment, we establish a causal relationship between viewing pornography and increased unethical behavior and show that this relationship is mediated by dehumanization. Using a survey, we generalize our findings to a nationally representative sample and find that the relationship between pornography consumption and unethical behavior is evident in the representative sample.

The experiment provides evidence with strong internal validity, while the survey results increase confidence in the external validity of our results. The fact that the relationship can be seen in both experimental and survey evidence indicates a strong positive relationship between pornography consumption and unethical behavior, which has important implications for the business world. In the experiment, the condition of recalling pornography occurred just prior to the ethical dilemma and decision. This implies that employees who view pornography at work and who are then faced with ethical decisions are more likely to act unethically.

Because pornography increases unethical behavior and the effect stems from an increased propensity to dehumanize others, our results have implications for numerous business and organizational decisions. For example, an increased tendency to lie to obtain gain and to view others only as a means to an end is likely to be highly detrimental to team effectiveness and cooperation. In addition, treating customers like objects rather than respecting them is likely to reduce customer satisfaction. Also, organizations' ability to retain and develop talented women may be undermined when employees, particularly those in leadership positions, consume pornography and more aggressively engage in dehumanizing behavior. Finally, increased employee

\footnotetext{
26 The differences in our results compared to Buzzell (2005) concerning education and income may be influenced by our study using data 15 years after the data collected in Buzzell (2005).
} 
propensity to dehumanize co-workers is likely to increase the incidence of sexual harassment or hostile work environments, both of which can decrease firm productivity and lead to costly litigation.

Finally, dehumanization has been linked to other negative behaviors in addition to unethical behavior including increased propensity to delegitimize others (Bar-Tal 2000), increased aggression (Greitemeyer and Mclatchie 2011; Rudman and Mescher 2012), and decreased willingness to work with others productively (Andrighetto et al. 2014; Cuddy et al. 2007). Thus, unethical behavior may be one of numerous consequences of employees' consumption of pornography; we leave to future work the task of more fully investigating these potential consequences.

Given the negative effects of pornography consumption we find in this study, what should business leaders do? While this study does not provide evidence-based suggestions, we highlight several possible actions and encourage future researchers to provide evidence-based suggestions. Companies could implement both preventive and detective controls to improve this issue (Christ et al. 2012, 2016). Preventive controls could include such things as internet filters and blocking devices to prevent individuals from accessing pornographic materials on company machines or over company Wi-Fi. This reduces access, but does not eliminate access as employees could still use personal cell phones to access pornography. Companies could implement policies that prohibit pornography consumption at work, and then with detective controls could enforce training requirements or penalties if employees are found violating these policies. Finally, companies could look to hire employees who are less likely to view pornography than others.

We recognize that this study is subject to certain limitations. Specifically, in our experiment, pornography was not explicitly shown to participants. We address this by priming participants with their own memories of viewing pornography. Future research may choose to address this with a more direct manipulation. Another limitation of our experiment is we cannot be sure that the recalling exercise has no effect on unethical behavior. Our results suggest that pornography affects unethical behavior by increasing dehumanization; we have no reason to expect that recalling exercise would impact dehumanization. Nonetheless, this possibility remains. Regarding our survey, we recognize that using only a single item scale to measure unethical behavior is not ideal. However, it is our hope that the survey results viewed concurrently with the experimental results provide convincing evidence on the impact of pornography on unethical behavior. Another remaining open question centers on how long the unethical effect of pornography lasts. We leave for future research the interesting question of effect persistence and length.

We also note that our definition of pornography is very broad. Future research may address how specific types of pornography affect different types of unethical behavior. Another fruitful avenue for future research is to examine how pornography consumption influences other workplace behaviors such as aggressive behaviors at work. We also encourage future research to address factors that can decrease the negative effect of viewing pornography on unethical behavior. Future research may also address the effect viewing pornography has on other decisions, such as risk assessment or financial decisions or if attitudes that are encouraged by some professions, like skepticism, intensify or attenuate the relation between pornography and unethical decisions. Another aspect that we are unable to capture in our study is the effect that workplace norms, such as ethical codes of conduct and organization culture, have on the relationship. Future research could address how workplace norms affect the relationship between viewing pornography and unethical behavior. Finally, we do not examine the possible link from less ethical behavior to viewing pornography and incremental unethical behavior as this feedback loop is outside of the scope of what we study, but this might be a fruitful avenue for future research.

Acknowledgements We thank Scott Emett, Kip Holderness, and workshop participants at Florida Atlantic University for helpful comments and suggestions.

\section{Compliance with Ethical Standards}

Conflict of interest All three authors declare they have no conflicts of interest.

Ethical Approval All procedures performed in studies involving human participants were in accordance with the ethical standards of the institutional and/or national research committee and with the 1964 Helsinki declaration and its later amendments or comparable ethical standards.

Informed Consent Informed consent was obtained from all individual participants included in the study.

Open Access This article is distributed under the terms of the Creative Commons Attribution 4.0 International License (http://creativeco mmons.org/licenses/by/4.0/), which permits unrestricted use, distribution, and reproduction in any medium, provided you give appropriate credit to the original author(s) and the source, provide a link to the Creative Commons license, and indicate if changes were made.

\section{Appendix 1: Items Used to Measure Delay Discounting Adopted from Kirby and Marakovic (1996)}

Participants were presented with the following instructions and situations to measure the level of delay discounting.

For the following hypothetical situations, please select the option you would prefer. 
For the following hypothetical situations, please select the option you would prefer.

Would you rather receive $\$ 30$ tonight or $\$ 85$ in 14 days? $\$ 30$ tonight

Would you rather receive $\$ 40$ tonight or $\$ 55$ in 25 days? $\$ 40$ tonight

Would you rather receive $\$ 67$ tonight or $\$ 85$ in 35 days? $\$ 67$ tonight

Would you rather receive $\$ 34$ tonight or $\$ 35$ in 43 days? \$34 tonight

Would you rather receive $\$ 15$ tonight or $\$ 35$ in 10 days? $\$ 15$ tonight

Would you rather receive $\$ 32$ tonight or $\$ 55$ in 20 days? \$32 tonight

Would you rather receive $\$ 83$ tonight or $\$ 85$ in 35 days? $\$ 83$ tonight

Would you rather receive $\$ 21$ tonight or $\$ 30$ in 75 days? $\$ 21$ tonight

Would you rather receive $\$ 48$ tonight or $\$ 55$ in 45 days? $\$ 48$ tonight

Would you rather receive $\$ 40$ tonight or $\$ 65$ in 70 days? $\$ 40$ tonight

Would you rather receive $\$ 25$ tonight or $\$ 35$ in 25 days? $\$ 25$ tonight

Would you rather receive \$25 tonight or \$35 in 25 days? \$25 tonight

Would you rather receive $\$ 65$ tonight or $\$ 70$ in 50 days? $\$ 65$ tonight

Would you rather receive \$24 tonight or \$55 in 10 days? \$24 tonight

Would you rather receive $\$ 30$ tonight or $\$ 35$ in 20 days? \$30 tonight

Would you rather receive $\$ 53$ tonight or $\$ 55$ in 55 days? $\$ 53$ tonight

Would you rather receive $\$ 47$ tonight or $\$ 60$ in 50 days? $\$ 47$ tonight

Would you rather receive $\$ 40$ tonight or $\$ 70$ in 20 days? $\$ 40$ tonight

Would you rather receive $\$ 50$ tonight or $\$ 80$ in 70 days? $\$ 50$ tonight

Would you rather receive $\$ 45$ tonight or $\$ 70$ in 35 days? $\$ 45$ tonight

Would you rather receive $\$ 27$ tonight or $\$ 30$ in 35 days? $\$ 27$ tonight

Would you rather receive $\$ 16$ tonight or $\$ 30$ in 35 days? $\$ 16$ tonight
$\$ 85$ in 14 days $\mathrm{O}$

$\$ 55$ in 25 days<smiles>O</smiles>

$\$ 85$ in 35 days 0

$\$ 35$ in 43 days 0

$\$ 35$ in 10 days $\mathrm{O}$

$\$ 55$ in 20 days 0

$\$ 85$ in 35 days $\mathrm{O}$

$\$ 30$ in 75 days 0

$\$ 55$ in 45 days $\mathrm{O}$

$\$ 65$ in 70 days O

$\$ 35$ in 25 days O

$\$ 70$ in 50 days $\mathrm{O}$

$\$ 55$ in 10 days O

$\$ 35$ in 20 days 0

$\$ 55$ in 55 days O

$\$ 60$ in 50 days O

$\$ 70$ in 20 days $\mathrm{O}$

$\$ 80$ in 70 days O

$\$ 70$ in 35 days 0

$\$ 30$ in 35 days O

$\$ 30$ in 35 days $\mathrm{O}$ 


\section{Appendix 2: Items Used to Measure Dehumanization Adopted from Leyens et al. (2001)}

This is a screen shot of the items used to measure dehumanization.

\begin{tabular}{|c|c|c|c|c|c|c|c|}
\hline & Very Unlikely & Unlikely & $\begin{array}{l}\text { Somewhat } \\
\text { Unlikely }\end{array}$ & $\begin{array}{l}\text { Neither } \\
\text { Likely nor } \\
\text { Unlikely }\end{array}$ & $\begin{array}{l}\text { Somewhat } \\
\text { Likely }\end{array}$ & Likely & Very Likely \\
\hline Resentment & 0 & 0 & 0 & 0 & 0 & 0 & 0 \\
\hline Pleasure & 0 & 0 & 0 & 0 & 0 & 0 & 0 \\
\hline Shame & 0 & 0 & 0 & 0 & 0 & 0 & 0 \\
\hline Love & 0 & 0 & 0 & 0 & 0 & 0 & 0 \\
\hline Excitement & 0 & 0 & 0 & 0 & 0 & 0 & 0 \\
\hline Admiration & 0 & 0 & 0 & 0 & 0 & 0 & 0 \\
\hline Anger & 0 & 0 & 0 & 0 & 0 & 0 & 0 \\
\hline Fear & 0 & 0 & 0 & 0 & 0 & 0 & 0 \\
\hline
\end{tabular}

\section{References}

Andrighetto, L., Baldissarri, C., Lattanzio, S., Loughnan, S., \& Volpato, C. (2014). Human-itarian aid? Two forms of dehumanization and willingness to help after natural disasters. British Journal of Social Psychology, 53(3), 573-584.

Baltazar, A., Helm, H. W., McBride, D., Hopkins, G., \& Stevens, J. V. (2010). Internet pornography use in the context of external and internal religiosity. Journal of Psychology and Theology, $38,32-40$.

Bandura, A. (1986). Social foundations of thought and action: A social cognitive theory. Englewood Cliffs, NJ: Prentice-Hall.

Bandura, A. (1991). Social cognitive theory of moral thought and action. In W. M. Kurtines \& J. L. Gewirtz (Eds.), Handbook of moral behavior and development: Theory, research and applications (Vol. 1, pp. 71-129). Hillsdale, NJ: Lawrence Erlbaum Associates Inc.

Bandura, A. (1999). Moral disengagement in the perpetration of inhumanities. Personality and Social Psychology Review, 3(3), 193-209.

Bar-Tal, D. (2000). Shared beliefs in a society: Social psychological analysis. Thousand Oaks, CA: Sage Publications.

Bergstresser, D., \& Philippon, T. (2006). CEO incentives and earnings management. Journal of Financial Economics, 80(3), 511-529.

Berinsky, A. J., Huber, G. A., \& Lenz, G. S. (2012). Evaluating online labor markets for experimental research: Amazon.com's Mechanical Turk. Political Analysis, 20(3), 351-368.

Bridges, A. J., Wosnitzer, R., Scharrer, E., Sun, C., \& Liberman, R. (2010). Aggression and sexual behavior in best-selling pornography videos: A content analysis update. Violence Against Women, 16(10), 1065-1085.

Buzzell, T. (2005). Demographic characteristics of persons using pornography in three technological contexts. Sexuality and Culture, 9(1), 28-48.

Buzzell, T., Foss, D., \& Middleton, Z. (2006). Explaining use of online pornography: A test of self-control theory and opportunities for deviance. Journal of Criminal Justice and Popular Culture, 13(2), 96-116.
Carroll, J. S., Padilla-Walker, L. M., Nelson, L. J., Olson, C. D., McNamara Barry, C., \& Madsen, S. D. (2008). Generation XXX: Pornography acceptance and use among emerging adults. Journal of Adolescent Research, 23(1), 6-30.

Chesson, H. W., Leichliter, J. S., Zimet, G. D., Rosenthal, S. L., Bernstein, D. I., \& Fife, K. H. (2006). Discount rates and risky sexual behaviors among teenagers and young adults. Journal of Risk and Uncertainty, 32(3), 217-230.

Christ, M. H., Emett, S. A., Summers, S. L., \& Wood, D. A. (2012). The effects of preventive and detective controls on employee performance and motivation. Contemporary Accounting Research, 29(2), 432-452.

Christ, M. H., Emett, S. A., Tayler, W. B., \& Wood, D. A. (2016). Compensation or feedback: Motivating performance in multidimensional tasks. Accounting, Organizations and Society, 50, 27-40.

CNBC. (2009). Porn at work: Recognizing a sex addict. Retrieved September 22, 2017, from https://www.cnbc.com/id/31922685.

CNN. (2010). Report: SEC staffers watched porn as economy crashed. Retrieved May 14, 2018, from http://www.cnn.com/2010/POLIT ICS/04/23/sec.porn/index.html.

Cohen, D. A., Dey, A., \& Lys, T. Z. (2008). Real and accrual-based earnings management in the pre-and post-Sarbanes-Oxley periods. The Accounting Review, 83(3), 757-787.

Conlin, M. (2000). Workers, surf at your own risk. Retrieved May 14, 2018, from https://www.bloomberg.com/news/articles/2000-0611/workers-surf-at-your-own-risk.

Cooper, A. (1998). Sexuality and the Internet: Surfing into the new millennium. CyberPsychology \& Behavior, 1(2), 187-193.

Cooper, A., Delmonico, D. L., \& Burg, R. (2000). Cybersex users, abusers, and compulsives: New findings and implications. Sexual Addiction \& Compulsivity: The Journal of Treatment and Prevention, 7(1-2), 5-29.

Cooper, A., \& Griffin-Shelley, E. (2002). Introduction: The Internet: The next sexual revolution. In A. Cooper (Ed.), Sex and the Internet: A guidebook for clinicians (pp. 1-15). New York: Brunner $\&$ Routledge.

Covenant Eyes. (2015). Pornography statistics. Retrieved September 22, 2017, from http://www.covenanteyes.com/pornstats/. 
Crean, J. P., de Wit, H., \& Richards, J. B. (2000). Reward discounting as a measure of impulsive behavior in a psychiatric outpatient population. Experimental and Clinical Psychopharmacology, $8(2), 155-162$.

Cuddy, A. J. C., Rock, M. S., \& Norton, M. I. (2007). Aid in the aftermath of Hurricane Katrina: Inferences of secondary emotions and intergroup helping. Group Processes \& Intergroup Relations, 10(1), 107-118.

Davis, C., Patte, K., Curtis, C., \& Reid, C. (2010). Immediate pleasures and future consequences: A neuropsychological study of binge eating and obesity. Appetite, 54(1), 208-213.

Detert, J. R., Treviño, L. K., \& Sweitzer, V. L. (2008). Moral disengagement in ethical decision making: a study of antecedents and outcomes. Journal of Applied Psychology, 93(2), 374-391.

Dixon, M. R., Jacobs, E. A., \& Sanders, S. (2006). Contextual control of delay discounting by pathological gamblers. Journal of Applied Behavior Analysis, 39(4), 413-422.

Fagan, P. F. (2009). The effects of pornography on individuals, marriage, family and community. Washington DC: Marriage and Religion Research Institute.

Fawcett, T. W., McNamara, J. M., \& Houston, A. I. (2012). When is it adaptive to be patient? A general framework for evaluating delayed rewards. Behavioral Processes, 89(2), 128-136.

Ferrell, O. C. (2004). Business ethics and customer stakeholders. Academy of Management Perspectives, 18(2), 126-129.

Gabbiadini, A., Riva, P., Andrighetto, L., Volpato, C., \& Bushman, B. J. (2014). Interactive effect of moral disengagement and violent video games on self-control, cheating, and aggression. Social Psychological and Personality Science, 5(4), 451-458.

Goodman, J. K., Cryder, C. E., \& Cheema, A. (2013). Data collection in a flat world: The strengths and weaknesses of Mechanical Turk samples. Journal of Behavioral Decision Making, 26(3), 213-224.

Graham, J. R., Harvey, C. R., \& Rajgopal, S. (2005). The economic implications of corporate financial reporting. Journal of Accounting and Economics, 40(1-3), 3-73.

Greitemeyer, T., \& McLatchie, N. (2011). Denying humanness to others: A newly discovered mechanism by which violent video games increase aggressive behavior. Psychological Science, 22(5), 659-665.

Gubler, J. R., Herrick, S., Price, R. A., \& Wood, D. A. (2018). Violence, aggression, and ethics; the link between exposure to human violence and unethical behavior. Journal of Business Ethics, 147(1), 25-34.

Guynn, J. (2015). Google raising stakes on diversity. USA Today. Retrieved on June 1, 2018, from https://www.usatoday.com/story /tech/2015/05/05/google-raises-stakes-diversity-spending/26868 $359 \%$

Hald, G. M. (2006). Gender differences in pornography consumption among young heterosexual Danish adults. Archives of Sexual Behavior, 35(5), 577-585.

Hald, G. M., \& Malamuth, N. M. (2008). Self-perceived effects of pornography consumption. Archives of Sexual Behavior, 37(4), $614-625$.

Haslam, N. (2006). Dehumanization: An integrative review. Personality and Social Psychology Review, 10(3), 252-264.

Haslam, N., Bain, P., Douge, L., Lee, M., \& Bastian, B. (2005). More human than you: Attributing humanness to self and others. Journal of Personality and Social Psychology, 89(6), 937-950.

Henriques, I., \& Sadorsky, P. (1999). The relationship between environmental commitment and managerial perceptions of stakeholder importance. Academy of Management Journal, 42(1), 87-99.

Holderness, K. D., Huffman, A., \& Lewis-Western, M. (2018). Rank and file equity compensation and earnings management: Economic incentives and the Robin Hood effect. SSRN. https://ssrn. com/abstract $=2802714$.
Huang, G. (2017). Seeking women: 70 + companies that have set gender diversity targets. Forbes. Retrieved on June 1, 2018, from https://www.forbes.com/sites/georgenehuang/2017/02/14/seeki ng-women-40-companies-that-have-set-gender-diversity-targe ts/\#378060f4b112.

Huffington Post. (2013). Porn sites get more visitors each month than Netflix, Amazon and Twitter combined. Retrieved September 22, 2017, from http://www.huffingtonpost.com/2013/05/03/internetporn-stats_n_3187682.html,

Jones, T. M. (1991). Ethical decision making by individuals in organizations: An issue-contingent model. Academy of Management Review, 16(2), 366-395.

Kaptein, M. (2008). Developing a measure of unethical behavior in the workplace: A stakeholder perspective. Journal of Management, 34(5), 978-1008.

Kirby, K. N., \& Maraković, N. N. (1996). Delay-discounting probabilistic rewards: Rates decrease as amounts increase. Psychonomic Bulletin \& Review, 3(1), 100-104.

Kish-Gephart, J. J., Harrison, D. A., \& Treviño, L. K. (2010). Bad apples, bad cases, and bad barrels: meta-analytic evidence about sources of unethical decisions at work. Journal of Applied Psychology, 95(1), 1-31.

Klaassen, M. J., \& Peter, J. (2015). Gender (in) equality in Internet pornography: A content analysis of popular pornographic Internet videos. The Journal of Sex Research, 52(7), 721-735.

Kline, P. (2000). The handbook of psychological testing (2nd ed.). London: Routledge.

Lawyer, S. R. (2008). Probability and delay discounting of erotic stimuli. Behavioural Processes, 79(1), 36-42.

Lee, C. A., Derefinko, K. J., Milich, R., Lynam, D. R., \& DeWall, C. N. (2017). Longitudinal and reciprocal relations between delay discounting and crime. Personality and Individual Differences, 111, 193-198.

Leyens, J. P., Rodriguez-Perez, A., Rodriguez-Torres, R., Gaunt, R., Paladino, M. P., Vaes, J., et al. (2001). Psychological essentialism and the differential attribution of uniquely human emotions to ingroups and outgroups. European Journal of Social Psychology, 31(4), 395-411.

MacKillop, J. (2013). Integrating behavioral economics and behavioral genetics: delayed reward discounting as an endophenotype for addictive disorders. Journal of the Experimental Analysis of Behavior, 99(1), 14-31.

Maddox, A. M., Rhoades, G. K., \& Markman, H. J. (2011). Viewing sexually-explicit materials alone or together: Associations with relationship quality. Archives of Sexual Behavior, 40(2), 441-448.

Malamuth, N. M., \& Ceniti, J. (1986). Repeated exposure to violent and nonviolent pornography: Likelihood of raping ratings and laboratory aggression against women. Aggressive Behavior, 12(2), 129-137.

Malamuth, N. M., Hald, G. M., \& Koss, M. (2012). Pornography, Individual Differences in Risk and Men's Acceptance of Violence Against Women in a Representative Sample. Sex Roles, 66(7-8), 427-439.

Manning, J. C. (2006). The impact of internet pornography on marriage and the family: A review of the research. Sexual Addiction \& Compulsivity, 13(2-3), 131-165.

McDonald, T. (2018). How many people watch porn at work will shock you. Retrieved May 14, 2018, from https://sugarcooki e.com/2018/01/watch-porn-at-work/.

McKee, A. (2005). The objectification of women in mainstream pornographic videos in Australia. Journal of Sex Research, 42(4), 277-290.

McKee, A. (2007a). The positive and negative effects of pornography as attributed by consumers. Australian Journal of Communication, 34(1), 87-104. 
McKee, A. (2007b). The relationship between attitudes towards women, consumption of pornography, and other demographic variables in a survey of 1,023 consumers of pornography. International Journal of Sexual Health, 19(1), 31-45.

Moore, C., Detert, J., Baker, V., \& Mayer, D. (2012). Why employees do bad things: moral disengagement and unethical organizational behavior. Personnel Psychology, 65, 1-48.

NBC. (2018). More cases of federal workers watching porn on the job uncovered. Retrieved May 14, 2018, from https://www.nbcwa shington.com/investigations/Federal-Workers-Continue-Acces sing-Pornography-Government-Issued-Computers-481926621. html.

Negash, S., Sheppard, N. V. N., Lambert, N. M., \& Fincham, F. D. (2016). Trading later rewards for current pleasure: Pornography consumption and delay discounting. The Journal of Sex Research, 53(6), 689-700.

Ogas, O., \& Gaddam, S. (2012). A billion wicked thoughts: What the Internet tells us about sex and relationships (p. 2012). NY: Plume.

Owens, E. W., Behun, R. J., Manning, J. C., \& Reid, R. C. (2012). The impact of Internet pornography on adolescents: A review of the research. Sexual Addiction \& Compulsivity, 19(1-2), 99-122.

Paolacci, G., \& Chandler, J. (2014). Inside the Turk: Understanding Mechanical Turk as a participant pool. Current Directions in Psychological Science, 23(3), 184-188.

Papadaki, L. (2010). What is objectification? Journal of Moral Philosophy, 7(1), 16-36.

Peter, J., \& Valkenburg, P. M. (2007). Adolescents' exposure to a sexualized media environment and their notions of women as sex objects. Sex Roles, 56(5-6), 381-395.

Price, J., Patterson, R., Regnerus, M., \& Walley, J. (2016). How much more XXX is Generation X consuming? Evidence of changing attitudes and behaviors related to pornography since 1973 . The Journal of Sex Research, 53(1), 12-20.

Rachlin, H., \& Green, L. (1972). Commitment, choice and self-control. Journal of the Experimental Analysis of Behavior, 17(1), 15-22.

Regnerus, M., Gordon, D., \& Price, J. (2016). Documenting pornography use in America: a comparative analysis of methodological approaches. The Journal of Sex Research, 53(7), 873-881.

Rest, J. R. (1986). Moral development: Advances in research and theory. New York: Praeger.

Richters, J., Grulich, A. E., Visser, R. O., Smith, A., \& Rissel, C. E. (2003). Sex in Australia: Autoerotic, esoteric and other sexual practices engaged in by a representative sample of adults. Australian and New Zealand Journal of Public Health, 27(2), 180-190.

Rodriguez, M. (2015). The 5 most common unethical workplace behaviors. Behavior Science in the 21st Century Post, https://bsci2 1.org/the-5-most-common-unethical-workplace-behaviors/.

Romer, D., Duckworth, A. L., Sznitman, S., \& Park, S. (2010). Can adolescents learn self-control? Delay of gratification in the development of control over risk taking. Prevention Science, 11(3), 319-330.

Ropelato, J. (2014). Internet pornography statistics. Retrieved September 22, 2017, from http://www.ministryoftruth.me.uk/wp-conte nt/uploads/2014/03/IFR2013.pdf.

Rudman, L. A., \& Mescher, K. (2012). Of animals and objects: Men's implicit dehumanization of women and likelihood of sexual aggression. Personality and Social Psychology Bulletin, 38(6), $734-746$.

Saul, J. M. (2006). On treating things as people: Objectification, pornography, and the history of the vibrator. Hypatia, 21(2), 45-61.

Saville, B. K., Gisbert, A., Kopp, J., \& Telesco, C. (2010). Internet addiction and delay discounting in college students. The Psychological Record, 60(2), 273-286.
Schneider, J. P. (2000). Effects of cybersex addiction on the family: Results of a survey. Sexual Addiction \& Compulsivity: The Journal of Treatment and Prevention, 7(1-2), 31-58.

Short, M. B., Black, L., Smith, A. H., Wetterneck, C. T., \& Wells, D. E. (2012). A review of Internet pornography use research: Methodology and content from the past 10 years. Cyberpsychology, Behavior, and Social Networking, 15(1), 13-23.

Short, M. B., Kasper, T. E., \& Wetterneck, C. T. (2015). The relationship between religiosity and internet pornography use. Journal of Religion and Health, 54(2), 571-583.

Stewart, D. N., \& Szymanski, D. M. (2012). Young adult women's reports of their male romantic partner's pornography use as a correlate of their self-esteem, relationship quality, and sexual satisfaction. Sex Roles, 67(5-6), 257-271.

Suddath, C. (2014). Watching porn at the office: 'Extremely common'. Retrieved May 10, 2018, from https://www.bloomberg. com/news/articles/2014-10-09/watching-porn-at-the-office-extre mely-common.

Suri, S., Goldstein, D. G., \& Mason, W. A. (2011). Honesty in an Online Labor Market. Human Computation, 11(11), 61-66.

Treviño, L. K., Weaver, G. R., \& Reynolds, S. J. (2006). Behavioral ethics in organizations: A review. Journal of Management, 32(6), 951-990.

Trope, Y., \& Liberman, N. (2010). Construal-level theory of psychological distance. Psychological Review, 117(2), 440-463.

Van den Bergh, B., Dewitte, S., \& Warlop, L. (2008). Bikinis instigate generalized impatience in intertemporal choice. Journal of Consumer Research, 35(1), 85-97.

Ward, L. M. (2002). Does television exposure affect emerging adults' attitudes and assumptions about sexual relationships? Correlational and experimental confirmation. Journal of Youth and Adolescence, 31(1), 1-15.

Ward, L. M., \& Friedman, K. (2006). Using TV as a guide: Associations between television viewing and adolescents' sexual attitudes and behavior. Journal of Research on Adolescence, 16(1), $133-156$

Watley, L. D., \& May, D. R. (2004). Enhancing moral intensity: The roles of personal and consequential information in ethical decision-making. Journal of Business Ethics, 50(2), 105-126.

Welsh, D., Ordonez, L., Snyder, D., \& Christian, M. (2015). The slippery slope: How small ethical transgressions pave the way for larger future transgressions. Journal of Applied Psychology, 1, $114-127$.

Willoughby, B. J., Carroll, J. S., Nelson, L. J., \& Padilla-Walker, L. M. (2014). Associations between relational sexual behaviour, pornography use, and pornography acceptance among US college students. Culture, Health \& Sexuality, 16(9), 1052-1069.

Wilson, M., \& Daly, M. (2004). Do pretty women inspire men to discount the future? Proceedings of the Royal Society of London B: Biological Sciences, 271(Suppl 4), S177-S179.

Wright, P. J. (2013). U.S. males and pornography, 1973-2010: Consumption, predictors, correlates. Journal of Sex Research, 50(1), 60-71.

Wright, P. J., Tokunaga, R. S., \& Bae, S. (2014). More than a dalliance? Pornography consumption and extramarital sex attitudes among married US adults. Psychology of Popular Media Culture, 3(2), 97-109.

Yam, K. C., \& Reynolds, S. J. (2016). The effects of victim anonymity on unethical behavior. Journal of Business Ethics, 136(1), 13-22.

Yang, X. Y. (2016). Is social status related to internet pornography use? Evidence from the early 2000s in the United States. Archives of Sexual Behavior, 45(4), 997-1009.

Publisher's Note Springer Nature remains neutral with regard to jurisdictional claims in published maps and institutional affiliations. 